\title{
O tempo em Agnes Heller: contribuições para a reflexão sobre o mundo do trabalho
}

Time in Agnes Heller:

a contribution to reflections on the world of work

Gleny Terezinha Duro Guimarães*

\begin{abstract}
Resumo - A classe trabalhadora vivencia um contexto de espoliação regido pela financeirização do capital, cujos rebatimentos estão associados às atuais configurações no mundo do trabalho. Um dos elementos desta configuração é o tempo. Neste artigo, temos o objetivo de refletir sobre os impactos do tempo no mundo do trabalho. Tratase de uma pesquisa teórica, vinculada ao método dialético, a partir dos fundamentos ontológicos propostos por Agnes Heller. A finalidade é contribuir epistemologicamente com as reflexões realizadas pelo Serviço Social para compreender o que vem ocorrendo no século $\mathrm{XXI}$, a partir dos malefícios provocados pela reestruturação produtiva, marcando a sociedade com o ferrete da desigualdade social e da exploração econômica dos trabalhadores. Concluímos demonstrando o quanto o tempo está relacionado com alguns aspectos do mundo do trabalho, que se vinculam à esfera da particularidade e, nesta esfera, não promovem mudanças em relação à precarização das condições de trabalho. De forma propositiva, defendemos que uma política pública de proteção do trabalho precisa ser concebida na esfera da genericidade quando predomina o poder coletivo da classe trabalhadora.
\end{abstract}

Palavras-chave: vida cotidiana; tempo; trabalho.

\begin{abstract}
The working class is experiencing a context of despoilment ruled by the financialization of capital, whose repercussions are associated with the current configurations of the world of work. One of the elements of this configuration is time. In this article, we aim to reflect on the impact of time on the world of work. It is a theoretical research study associated with the dialectical method, based on the ontological foundations proposed by Agnes Heller. The purpose is to contribute epistemologically to the reflections of Social Work aiming to understand what has been happening in the 21 st century, based on the evils caused by the restructuring of production, marking society with the stigma of social inequality and the economic exploitation of workers. We conclude showing to what extent time is related to some
\end{abstract}

* Prof ${ }^{-}$Dr ${ }^{a}$ titular do Curso de Serviço Social da PUC-RS. Possui pós-doutorado, doutorado e mestrado em Serviço Social e graduação em Pedagogia e Serviço Social. Coordenadora desde 1996 do Grupo de Estudos e Pesquisas sobre Cotidiano, Trabalho e Território - GPsT. Correspondência: Av. Ipiranga 6681, prédio 15, sala 325 Bairro Partenon, Porto Alegre, RS, CEP: 90619-900. Email: <gleny@pucrs.br>. 
aspects of the world of work, which are connected to the sphere of particularity, and in this sphere they do not promote changes regarding the precariousness of working conditions. As a proposition, we advocate that a public policy of work protection must be conceived in the sphere of genericity when the collective power of the working class predominates.

Keywords: everyday life, time, work.

\section{Introdução}

Trabalho e tempo fazem parte da vida do Ser Social e estão tão impregnados na condição humana que nem percebemos sua vinculação ontológica. Esse vínculo não é tão óbvio quanto parece; por isso, refletir detidamente sobre esta relação poderá trazer novas compreensões sobre o mundo do trabalho numa sociedade marcada pela desigual condição econômica e social.

O tempo se manifesta na vida cotidiana e está tão incorporado nas relações do mundo do trabalho que acaba desempenhando uma função estruturante na organização econômica, política e cultural da complexa realidade contemporânea. Um dos aspectos que assombra todos os que sofrem os malefícios do capitalismo se refere à falta de tempo, e está associado ao trabalho abstrato. Este é um aspecto fundamental que indica o quanto a divisão sociotécnica do trabalho, legitimada pelo hodierno processo de reestruturação produtiva, está associada ao padrão de flexibilização, precarização e desregulamentação dos direitos sociais do trabalhador.

Trabalho é uma categoria ontológica e várias são as concepções que norteiam sua compreensão. Na perspectiva do materialismo histórico dialético, ele é fundante da ontologia do Ser Social em Marx e Lukács, compreendendo toda ação que o homem realiza para satisfazer às necessidades da existência humana, sejam biológica, econômica, cultural ou política. Portanto, trabalho diz respeito à constituição do Ser Social e da humanidade, encontrando-se em qualquer esfera da vida cotidiana; de modo que Wilde (2013, p. 25) diz entendê-lo "[...] simplesmente como atividade de qualquer espécie". Além disso, toda esta ação está indissociavelmente imbricada com a dimensão do tempo que governa os mecanismos de reprodução da sociedade. Isso nos mostra o quanto tempo e trabalho estão inter-relacionados na esfera da vida cotidiana, considerando que estes

${ }^{1}$ Todos os grifos apresentados neste artigo são da própria autora, com o objetivo de ressaltar o tema da reflexão. 


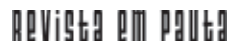

\} O TEMPO EM AGNES HELLER - GUIMARÃES, G. T. D. \}

DOI: $10.12957 /$ REP.2016.27855

estão associados à crescente desigualdade social e econômica vivenciada pela classe trabalhadora.

A desigualdade social, na contemporaneidade, tem se acirrado cada vez mais, e é visivelmente detectada na vida cotidiana do trabalhador excluído do mercado formal ou informal de trabalho. Para a filósofa Heller (1999, p. 27), a desigualdade social continua a cindir a sociedade em duas classes: "[...] uma minoria que fará um trabalho altamente qualificado em campos sofisticados aprenderá muito, saberá muito, ganhará muito e trabalhará por períodos mais longos", enquanto que com a outra classe acontece o inverso: "[...] haverá uma maioria fazendo trabalho inferior em poucas horas ou mesmo não fazendo nenhum trabalho, ganhando pouco, aprendendo pouco $[\ldots]^{\prime \prime}$.

Na vida cotidiana, a desigualdade social está presente em várias dimensões; no que se refere à desigualdade de classe, esta é gerada pelo modo de produção capitalista: "[...] é uma desigualdade que tem as suas raízes na estrutura e no desenvolvimento normal da vida econômica" (MANDEL, 1982, p. 11). Estas raízes têm como cerne a questão social, que historicamente foi sendo gestada pela dominação de uma classe sobre a outra. Devemos lembrar que as múltiplas expressões da questão social têm sido o escopo da intervenção cotidiana dos assistentes sociais, sendo compreendida como o "conjunto das expressões das desigualdades da sociedade capitalista madura, que tem uma raiz em comum: a produção social é cada vez mais coletiva, o trabalho torna-se mais amplamente social, enquanto a apropriação dos seus frutos mantém-se privada" (IAMAMOTO, 2005, p. 27).

O monopólio da riqueza socialmente produzida tem sido historicamente constituído sob o domínio de uma classe sobre a outra. Segundo Mandel (1982), a luta entre as classes, de acordo com o período histórico, pode ser classificada da seguinte maneira: no período do Império, as classes se dividiam entre camponeses, de um lado, e sacerdotes e senhores, do outro; na Antiguidade greco-romana, dividiam-se entre escravos e senhores dos escravos; na Alta Idade Média, as classes eram constituídas pelos servos e pelos senhores feudais; e, no capitalismo, entre trabalhadores assalariados e os donos dos meios de produção, a burguesia. "Mas, fosse qual fosse a forma assumida, a exploração de uma parte da sociedade pela outra é um fato comum a todos os séculos passados" (MARX; ENGELS, 1998, p. 29).

As múltiplas expressões da questão social, que denunciam a desigualdade social, estão relacionadas às configurações do mundo do trabalho; além disso, estão atreladas ao modo de produção e a um tempo a ele associado. Assim, sociedade, trabalho e tempo ${ }^{2}$ coexistem e formam a estrutura da vida cotidiana, merecendo ser objeto de reflexão, pois nem sempre são

\footnotetext{
${ }^{2}$ A filosofia do tempo inicia com Santo Agostinho, no período de transição entre a Antiguidade e a Idade Média, e continua sendo objeto de reflexão na filosofia. Essa trajetória histórica não é o foco neste artigo.
} 
visivelmente relacionados ao tipo de sociedade em que nos inserimos. Dessa maneira, a invisibilidade é um mecanismo ideológico para a dominação.

Neste artigo, fazemos uma interpretação do que a filósofa húngara propõe sobre o tempo na teoria da vida cotidiana ${ }^{3}$. O tempo influencia a vida cotidiana de forma singular, mas nem sempre nos debruçamos sobre este tema para refletir acerca das determinações do tempo na vida cotidiana dos trabalhadores. Estes que, contra a corrente do desenvolvimento capitalista, procuram formas de sobrevivência e superação da exploração dominante.

Numa perspectiva ontológica, de que forma o tempo se relaciona com as atuais configurações do mundo do trabalho? Esta é a pergunta que norteia as reflexões neste artigo.

\section{Tempo na teoria do cotidiano}

A existência do Ser Social está vinculada à existência da vida cotidiana, e nenhum indivíduo ${ }^{4}$, em qualquer período histórico, deixou de vivenciá-la. Isso significa dizer que o cotidiano é inerente à vida do ser humano, e é no cotidiano que tudo ocorre como primeira instância de sua existência. Parece um tema óbvio, mas não é. A categoria do cotidiano de Heller $(1989 ; 1991)$ apresenta fundamental contribuição ao Serviço Social, pois nos proporciona elementos para refletir ontologicamente sobre o ser humano e sua existência na sociedade.

Assim, Heller (1989, p. 20) nos diz: "a vida cotidiana não está fora da história, mas no centro do acontecer histórico: é a verdadeira essência da substância social". Lefebvre (1991, p. 44) compartilha a importância de uma teoria sobre a vida cotidiana enquanto espaço criador da humanidade:

Revelar a riqueza escondida sob a aparente pobreza do cotidiano, descobrir a profundeza sob a trivialidade, atingir o extraordinário do ordinário, só era claro e talvez verdadeiro, quando feito com base na vida dos trabalhadores, distinguindo-se, para exaltá-la, a sua capacidade criadora.

Outros autores ${ }^{5}$ que teorizam sobre a vida cotidiana exibem um consenso ao considerar que o cotidiano contém uma relação dialética entre

\footnotetext{
${ }^{3}$ Cabe destacar ao leitor principiante em Agnes Heller que, além de Teoria do cotidiano, a autora tem uma vasta produção intelectual, na qual alguns temas são discutidos, tais como: teoria dos sentimentos, período do Renascimento, Pós-Modernismo, necessidades radicais, teoria do valor etc.

${ }^{4} \mathrm{O}$ indivíduo, termo utilizado por Heller, é compreendido enquanto Ser Social, que congrega a esfera da particularidade e a esfera da genericidade. Não se refere ao individualismo proveniente da concepção ideológica do liberalismo (GUIMARÃES, 2000).

${ }^{5}$ Autores como Lefebvre, Kosik e Lukács também teorizaram sobre a vida cotidiana. O leitor poderá constatar algumas diferenças e semelhanças em Guimarães (2002b).
} 


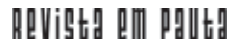

\} O TEMPO EM AGNES HELLER - GUIMARÃES, G. T. D. \}

DOI: $10.12957 /$ REP.2016.27855

o extraordinário e o ordinário, entre o comum e o excepcional, entre o particular e o genérico.

O cotidiano é a dimensão do senso comum, com todo o sofrimento, prazer, alegria, tristeza, destruição e construção que somente o ser humano é capaz de viver. A dimensão da cotidianidade estaria no circuito de tensão permanente conectado com a possibilidade de sermos seres humanos melhores, a possibilidade da grande transformação que somente o próprio homem poderá realizar. (GUIMARÃES, 2002b, p. 34).

Na relação entre vida cotidiana e trabalho, a dimensão do tempo está imbricada e é determinante nas relações sociais, na constituição histórica do ser humano e das relações entre as classes. Na concepção de Heller (1991), o tempo possui algumas peculiaridades que incidem diretamente tanto no trabalho concreto quanto no trabalho abstrato. Uma das peculiaridades do tempo, na esfera do cotidiano, é o antropocentrismo, considerando que a centralidade da vida cotidiana é o indivíduo. Tudo converge para satisfazer a suas necessidades, isto é, propaga-se do centro de si mesmo para os outros e para o mundo externo. A esfera correspondente ao antropocentrismo do tempo é a particularidade, na qual a objetivação em-si ${ }^{6}$ se concretiza.

Um dos aspectos a ser considerado em relação ao tempo é que este "se refere a sua hora"7 (HELLER, 1991, p. 385). Esta definição diz respeito ao agora do particular, porque cada um vivencia o tempo de uma forma própria. O tempo acontece através de uma experiência vivida, centrada na particularidade, e ninguém poderá viver aquele tempo pelo outro. Neste sentido, o tempo é uma condição inalienável do ser humano, tal como respirar, alimentar-se e trabalhar. O trabalho, enquanto categoria central do materialismo histórico, é determinante para a constituição do modo de produção, porque através dele o ser humano transforma a natureza e desenvolve todas as atividades necessárias para sua produção e reprodução. Vale lembrar que o ser humano só se desenvolveu historicamente na sociedade em função da categoria trabalho; sem esta, a sociedade não se constituiria, permanecendo apenas a existência da natureza. Portanto, tempo e trabalho, na vida cotidiana, são indissociáveis. O tempo e o trabalho eclodem nas sutilezas da vida cotidiana e não nos damos conta do quanto estão entrelaçados, do quanto um determina o outro.

A partir da década de 1970, o mundo é invadido pelo receituário neoliberal, sob os fortes impactos do novo modelo de organização e pro-

\footnotetext{
${ }^{6}$ É na particularidade que as objetivações genéricas em-si se efetivam. “Nas objetivações genéricas em-si, o homem passa por um processo de apropriação de tudo aquilo que faz parte do seu cotidiano, desde qualquer tipo de material até a apreeñão do código linguístico, ou seja, é a apropriação dos instrumentos e produtos, costumes e linguagem" (GUIMARÃES, 2002a, p. 29).

${ }^{7} \mathrm{Na}$ versão em espanhol: "se refiere a su ahora".
} 
dução capitalista toyotista, que propaga as diretrizes da acumulação flexível. Este modelo tem afetado diretamente a vida dos trabalhadores assalariados; como diria Mészáros (2011, p. 69), "todas as categorias de trabalhadores qualificados e não qualificados: ou seja, obviamente, a totalidade da força de trabalho da sociedade".

$\mathrm{Na}$ base desta nova reconfiguração do capital, os determinantes políticos, econômicos e sociais implicam o tempo e a intensificação do trabalho via novas formas de gestão da força de trabalho (flexibilização das relações de trabalho, priorização do trabalho morto em detrimento do trabalho vivo, precarização das condições de trabalho, entre outros aspectos). Neste sentido, podemos constatar que o tempo dedicado ao trabalho produtivo, que afeta a totalidade dos trabalhadores, tem se materializado através da redução da jornada de trabalho diária ou semanal, expressando-se na falta de tempo para viver as outras dimensões da vida cotidiana.

A discussão da redução da jornada de trabalho configura-se como um ponto de partida decisivo, ancorado no universo da vida cotidiana, para, por um lado, permitir uma reflexão fundamental sobre o tempo, o tempo de trabalho, o autocontrole sobre o tempo de trabalho, e o tempo de vida. E, por outro, por possibilitar o afloramento de uma vida dotada de sentido fora do trabalho. (ANTUNES, 2003, p. 174).

O sentido do trabalho se objetiva através do tempo, e este possui como referência o que está sendo vivido no presente ${ }^{8}$, pois no passado o tempo é pretérito e no futuro o tempo ainda vai ser vivenciado; porém, dentre os tempos, o presente continua sendo a centralidade da vida cotidiana. Nas palavras da autora, "o sistema de referência do tempo cotidiano é o presente" (HELLER, 1991, p. 385). É através do tempo presente que ocorre a "integração do gênero humano com a vida cotidiana" (HELLER, 1991, p. 385). Dessa maneira, o tempo presente afeta a vida cotidiana, principalmente no que se refere ao trabalho, e é percebido de forma diferente pelos indivíduos. Portanto, o tempo presente não é igual, não é vivido e nem se manifesta da mesma forma entre os homens. Contudo, o tempo coordena todas as ações práticas do ser humano, e estas estão interligadas com o ambiente natural e principalmente com o duplo sentido do trabalho - o trabalho concreto e o abstrato.

O duplo sentido do trabalho implica em tempo, e o tempo presente é um divisor entre o tempo pretérito e o tempo futuro; ele delimita, sem percebermos, a fração de minuto que já foi vivenciada em relação à fração de minuto que será vivenciada. Então, podemos dizer que o minuto que

\footnotetext{
${ }^{8}$ O termo presente, enquanto tempo verbal, tem um sentido teórico se estudar, analisar e explicar o tempo como fenômeno. O tempo enquanto substantivo masculino serve para designar um objeto que se deseja presentear a alguém, de modo que presente é algo que se oferece a outro ser humano, querendo homenageá-lo, prestigiá-lo. Fazendo um trocadilho, podemos dizer que o tempo presente é um presente da vida.
} 
está sendo vivenciado é, ao mesmo tempo, quase um minuto passado e quase um minuto futuro ${ }^{9}$. O tempo está tão interligado que não conseguimos definir o limite que separa a transição do minuto presente para o minuto do passado ou do futuro. O limite é tão tênue no momento presente que de fato só o distinguimos facilmente tendo como referência o tempo histórico. Neste, presente, passado e futuro estão claramente delimitados, o que não ocorre na esfera da particularidade, no tempo vivido, porque existe um paradoxo.

Este paradoxo se refere ao tempo que o tempo tem: o presente quase não se distingue do passado e do futuro, quase a ponto de se fundirem. Mas se pensarmos em termos de minutos ou horas, ou no tempo histórico, eles estão nitidamente separados. A unicidade e diversidade do tempo de fato não são lineares, mas mantêm uma relação dialética, na qual o tempo presente é a contradição entre o tempo pretérito e o tempo futuro.

Para o trabalhador, esses diferentes tempos podem significar processos de trabalho diferentes. Para a classe-que-vive-o-desemprego ${ }^{10}, 0$ tempo presente implica a sobrevivência diária; o tempo futuro, as possibilidades de ingresso no mercado de trabalho e a perspectiva de se inserir no sistema de proteção social. Para a classe-que-vive-do-trabalho, o presente pode significar a manutenção do emprego; o futuro, a estabilidade através da aposentadoria. Para a classe-que-vive-do-trabalho-autônomo, o presente significa a manutenção do trabalho cotidiano; o futuro, a busca pela estabilidade. Do ponto de vista do capital, o tempo presente significa maior produtividade no menor tempo possível, e o futuro, a materialização do trabalho excedente, sob a égide do trabalho abstrato que produz maisvalor.

Na concepção de Heller (1991, p. 386), os tempos se distinguem entre si, no sentido de que o pretérito nunca poderá ser modificado e "já não atua mais sobre o presente"; o futuro é "imprevisível" porque decorre do processo de objetivação; o presente é "incerto" porque pode ser alterado no mesmo instante em que está sendo vivenciado, em função das escolhas que constantemente estão sendo realizadas. Podemos perceber claramente o quanto o tempo futuro é imprevisível e o quanto o tempo presente é incerto ao pensarmos numa situação em que o ser humano tem de fazer uma escolha entre dois objetos: ao optar por um deles, poderá repentinamente trocar sua escolha pelo outro objeto; portanto, enquanto a ação não estiver concluída, o presente será incerto, antes e durante a objetivação do ser humano. Isto porque, como vimos, em qualquer momento a escolha poderá ser modificada, resultando em tempos futuros diferentes. Este argumento helleriano permite inferir que o pôr teleológico do trabalho nem sempre se determina de forma linear, na medida em que mudanças nas escolhas acarre-

\footnotetext{
${ }_{9}^{9} \mathrm{O}$ leitor que deseja aprofundar a ideia de fusão entre presente, passado e futuro poderá buscar na teoria das cordas uma compreensão da física quântica, porém, este não é o foco do presente artigo.

${ }^{10}$ Correlação aos termos utilizados por Antunes (2003).
} 
tarão igualmente em mudanças nos seus resultados. Em relação aos processos de trabalho, nem sempre a mudança nos tempos se torna possível, já que no trabalho abstrato o resultado é previsível, determinado pelo tempo de trabalho necessário à produção capitalista.

Presente, pretérito e futuro, enquanto dimensões do tempo, irão determinar a práxis no cotidiano e nas relações do mundo do trabalho. Para Heller, o tempo está inter-relacionado com a vivência da particularidade, e a consciência da dimensão do tempo, no cotidiano, "serve também para a orientação prática"11 dos momentos vivenciados.

Podemos perceber claramente a implicação entre o tempo passado, presente e futuro. O tempo reflete o movimento de construção da sociedade no qual presente, passado e futuro estão interconectados e se modificam constantemente; por isso o tempo é fluxo contínuo, isto é, tem pouca permanência, está em constante movimento, uma vez que existe apenas num instante da realidade, para no seguinte se transformar - uma perspectiva do legado heraclítico ${ }^{12}$. O tempo poderá ter um sentido oposto, por exemplo, ao pensarmos no trabalhador assalariado, subempregado ou desempregado; o tempo pode significar a ausência de movimento, como defendia Parmênides, principalmente quando sua atividade é rotineira, repetitiva e reificada.

O tempo é insuprimível da esfera da particularidade; mesmo que a ciência ${ }^{13}$, na esfera da genericidade, o explique, ele vai sempre prevalecer no cotidiano enquanto "experiência interior temporal, da duração"14, vivenciada pelo indivíduo. A questão é que o modo como o trabalhador percebe o tempo e se relaciona com ele vai repercutir no duplo sentido do trabalho, ou seja, no trabalho produtivo ou improdutivo. Esta repercussão está imbricada com as características do tempo que, na visão helleriana, são: a irreversibilidade, o limite (morte), a medida e divisão do tempo, o ritmo do tempo, o momento justo e o tempo vivido. Iremos refletir sobre cada um deles, relacionando-os com a categoria trabalho.

\section{Irreversibilidade do tempo}

A irreversibilidade, no âmbito filosófico, "se reduz à irreversibilidade dos acontecimentos e dos fatos"15, ou seja, a ciência considera o tempo irreversível. Ele é marcado pelos acontecimentos e fatos históricos, econômicos e sociais, e "enquanto conceito não aparece no pensamento

\footnotetext{
${ }_{11}$ Na versão em espanhol: "sirven también para la orientación práctica".

${ }^{12}$ Os clássicos da filosofia antiga indagavam pela arché ou pela phýsis, conceitos de grande influência. Parmênides defendia a ideia de permanência do ser, ou seja, que a unidade é constituída pela estabilidade, pela ausência de contradição e movimento. Heráclito se destaca por pensar exatamente o contrário ao defender a ideia de movimento e contradição, o que permitia a constituição dos opostos (REALE; ANTISERI, 2003).

${ }^{13}$ Heller cita o exemplo da Teoria da Relatividade de Einstein, que é vivenciada na vida cotidiana, mas que a ciência relaciona espaço e tempo.

${ }^{14} \mathrm{Na}$ versão espanhola, "la categoría de experiencia interior temporal, de la duración".

${ }^{15}$ Em espanhol: "[...] se reduce a la irreversibilidad de los acontecimientos y de los hechos".
} 
cotidiano"16. No entanto, é necessário considerar que a "irreversibilidade é parte orgânica de nossa consciência temporal cotidiana" (HELLER, 1991, p. 386). Isso significa que a irreversibilidade não se refere apenas às objetivações em-si, constituidoras da esfera da particularidade, mas ao pen-samento histórico decorrente de uma "consciência temporal"; portanto, ela se encontra também nas objetivações genéricas para-sii" (HELLER, 1991, p. 386).

A irreversibilidade que ocorre no âmbito da particularidade, em função de o sujeito não ter uma consciência temporal cotidiana na esfera da genericidade, faz com que ele aceite os fatos e acontecimentos do passado, demonstrando um saudosismo romântico, expresso em afirmações como "naquele tempo (passado) o trabalho era melhor". Desta forma, o sujeito se resigna ao passado, o que vai gerando, no âmbito particular, uma passividade, um comodismo e uma aceitação natural dos fatos.

Geralmente este tipo de percepção é acompanhado de uma explicação de cunho religioso, que justifica a ação praticada no passado, em nome de um dogma. A necessidade de uma fé religiosa é uma das características da vida cotidiana e "costuma ser mais intensa e mais incondicional" no âmbito da particularidade (HELLER, 1989, p. 33). A irreversibilidade, na esfera da particularidade, se relaciona com o trabalho produtivo ao capital na medida em que o indivíduo pensa que as relações e as condições de trabalho não podem ser alteradas, pois desde o passado o trabalho é desenvolvido de uma determinada forma e assim deverá permanecer. Isso acaba alicerçando passividade e conformidade diante da realidade, bem como reforçando a perspectiva do trabalho alienado.

Para a filósofa húngara, o sujeito particular não consegue aceitar conscientemente a irreversibilidade do tempo passado e sente a necessidade de buscar na religião a explicação para aceitar os fatos negativos já vivenciados ou causados. Essa religiosidade também não favorece a percepção das condições materiais e de exploração que o trabalhador sofre durante a jornada de trabalho, uma vez que ele encontra na religiosidade uma forma de redimir a culpa através do arrependimento, considerando que "a vida eterna cumpre uma função de reparação ao infinito"18. Ou seja, quanto mais o sujeito tiver consciência da irreversibilidade do passado, "menor será sua necessidade religiosa" (HELLER, 1991, p. 386) e maior é a possibilidade de perceber a precarização das condições de trabalho a que geralmente está submetido. A partir da concepção helleriana de aceitação da irreversibilidade, são exemplos as comunidades naturalistas, cuja base foi a moral do estoicismo e do epicurismo.

É interessante lembrar que o epicurismo busca sentido na vida através do prazer e, segundo ele, a felicidade do ser humano decorre do

\footnotetext{
${ }^{16}$ Em espanhol: "[...] en cuanto concepto no aparece en el pensamiento cotidiano".

17 "A partir dessas objetivações (...) o homem deixa de estar centrado numa formação em-si e entra em contato intencional e conscientemente com a genericidade. Heller considera como objetivações genéricas para-si: a filosofia, a moral, a arte, a ciência e a religião" (GUIMARÃES, 2000, p. 30).

${ }^{18}$ Em espanhol: "[...] la vida eterna cumple una función de reparación en el infinito".
} 


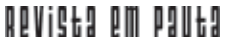

\} O TEMPO EM AGNES HELLER - GUIMARÃES, G. T. D. \}

DOI: $10.12957 /$ REP.2016.27855

contato com a natureza, com uma vida saudável, contra qualquer forma de violência. O estoicismo, por sua vez, complementa um tipo de sistema filosófico em que o ser humano deve seguir as leis da natureza, explicando a vida por meio de um ordenamento divino. Este sistema filosófico influencia até hoje algumas ideologias, como a dos naturalistas, cujo objetivo é atingir a felicidade através da qualidade de vida, mantendo o corpo e a mente saudáveis, de acordo com as leis da natureza e a busca pela paz de espírito (SIGNIFICADOS, 2015).

Relacionando essa questão à compreensão helleriana, o sistema moral dos epicureus e dos estoicos aceita a irreversibilidade do tempo não em decorrência de uma opção religiosa, mas por um modo e concepção de vida. Atualmente há comunidades naturalistas, mas em termos de resistência à acumulação capitalista, esse movimento ainda é insignificante diante da exploração da força de trabalho.

A religião, ao contrário, favorece a incapacidade de aceitar a irreversibilidade do tempo. A famosa frase de Marx, "a religião é o ópio do povo", revela o quanto a religião, sob o dogma e a fé incondicional, é capaz de dominar os trabalhadores explorados no processo produtivo e econômico, através da alienação em relação ao trabalho. Ideologicamente, a religião desempenha um papel de aceitação, pois o indivíduo encontra um sistema de explicação da realidade, tornando-o preso a ritos e costumes. Desempenha, além disso, um papel fundamental na impossibilidade de favorecimento das condições necessárias para o desenvolvimento da consciência temporal, isto é, da consciência de classe. A consciência temporal não seria alcançada pela percepção da religião, porque esta atua sobre a particularidade do indivíduo. Ideologicamente, ela se torna um forte aliado do poder econômico das classes dominantes ao induzir o indivíduo à aceitação do modo de produção estabelecido em cada período histórico.

O tempo passado existe através dos fatos ocorridos, mas pode-se descrevê-lo de formas diferentes. Não é possível mudar o passado, mas pode-se mudar a narrativa dos fatos históricos. O tempo é um problema metafísico e, por isso, podemos nos perguntar: o passado existe, ou o que existe é a percepção dele? De fato, o passado existe, mas é necessário relativizar a verdade contada, porque a maioria dos fatos históricos foi narrada pelas classes dominantes, razão pela qual a visão histórica já está contaminada. Imagine como seria a história do Brasil se tivesse sido contada e registrada através da força de trabalho dos indígenas, como seriam diferentes as narrativas!

\section{Limite do tempo}

O limite é outra característica do tempo. Ao falar sobre este conceito, Heller (1991) se refere ao limite da vida, que é a morte; ou seja, o 
tempo na relação com a finitude da vida humana. A morte e a irreversibilidade do tempo são acompanhadas pelo sentimento de inconformidade, característica que se apresenta no âmbito da particularidade. A morte está presente no pensamento e na ação prática do ser humano como marco do limite da vida. A consequência deste pensamento é que, em vez de o ser humano estar cogitativo na vida, ele tem como ponto de referência a morte; em outras palavras, o limite é a morte, e não a vida. Nesta interpretação, existe uma mudança de perspectiva que irá gerar formas diferentes de ação e pensamento do indivíduo.

Para Heller (1991, p. 387), numa perspectiva moral, se não houvesse a expectativa da morte, os homens, por natureza, seriam honestos, "porque a desonestidade é frequentemente uma consequência da falta de tempo: o temor a perder para sempre o que não se havia obtido hoje"19. Este pensamento justificaria as ações imediatas, pragmáticas e utilitaristas quando abarcadas na desonestidade. Portanto, para a autora, a perspectiva da morte influencia de alguma forma as ações humanas.

A "[...] morte aparece no horizonte da vida cotidiana como força motivadora de determinadas ações" 20 (HELLER, 1991, p. 387), e estas forças estão relacionadas com três tipos de atitude. Inicialmente, a insensibilidade é um fato natural, isto é, o sentimento vivenciado por "aqueles que ainda sentem a morte como um fato natural, e por isso não se ocupam dela" $(\text { HELLER, 1991, p. 387 })^{21}$. Estão indiferentes à morte, pois ela não os preocupa nem em relação aos outros nem em relação a si mesmos. Neste sentido, a autora explica que esta insensibilidade ou indiferença é decorrente da falta de "unicidade" em relação às pessoas, pois suas preocupações não se referem ao humano genérico. Esta perspectiva é facilmente identificada no mundo do trabalho como sendo o mal do século, ou seja, cada vez mais o adoecimento, o estresse e a depressão se manifestam em decorrência da precarização das condições de trabalho, da exploração e da pressão a que os trabalhadores são submetidos rotineiramente, muitas vezes sem nem se darem conta, pois o poder do capital está em suas formas invisibilizadas e subjugadas à produtividade do trabalho.

Diferentemente desta, a segunda atitude é o "temor da morte". O indivíduo já possui a unicidade na compreensão de si e dos demais e teme a morte frequentemente e/ou em momentos específicos na vivência do cotidiano, por exemplo, por ocasião de um acidente no trabalho. A finitude está sempre sendo lembrada, e por isso o ser humano assume uma posição de resignação em relação à morte, isto é, ela existe e a conformidade é a

\footnotetext{
${ }^{19}$ Em espanhol: "[...] porque la deshonestidad es a menudo una consecuencia de la falta de tiempo: el temor a perder para siempre lo que no se haya obtenido hoy".

${ }^{20}$ Em espanhol: "[...] la muerte aparece en el horizonte da la vida cotidiana como fuerza motivadora de determinadas acciones".

${ }^{21}$ Em espanhol: "[...] aquellos que aún sienten la muerte como un hecho natural, y por ello no se ocupan de ella".
} 


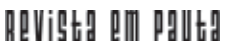

\} O TEMPO EM AGNES HELLER - GUIMARÃES, G. T. D. \}

DOI: $10.12957 /$ REP.2016.27855

solução. A terceira atitude é a aceitação da morte como um fato natural, através de acontecimentos previsíveis como a velhice e a doença, não se aceitando outro tipo de morte que seja provocada ou planejada pela ação do homem.

A aceitação da morte não significa resignação; significa, porém, ter a consciência de que ela é "parte orgânica da vida" (HELLER, 1991, p. 387-388), ou seja, de que a finitude decorre do processo de desenvolvimento do ser humano. Essa é uma atitude que percebe as gerações com distintos tempos, derivados da integração entre limite histórico e duração da vida na esfera da particularidade.

\section{Medida e divisão do tempo}

Heller (1991, p. 388) menciona outra característica, que é a "medida e a divisão do tempo". A partir do momento em que a humanidade sentiu necessidade de utilizar sistemas de numeração, especificamente os números naturais, a divisão do tempo passou a ser dimensionada pela "jornada"; ou seja, o número é o parâmetro para delimitar a jornada, considerando o ciclo natural do dia e da noite. A temporalidade é uma forma de duração e pode ser medida pela jornada da vida, que inclui a jornada de trabalho. A "divisão do tempo dentro de uma jornada" significa dividir o tempo em horas, minutos e segundos, delimitados pela duração de um dia e uma noite, o que corresponde a dizer que a jornada é de $24 \mathrm{~h}$.

Regular e controlar o tempo são características do mundo do trabalho, e um dos referenciais mais utilizados foi o tempo de jornada a que o trabalhador passa a ser subordinado. Isso ocorre desde que a jornada de trabalho era de 16h diárias; contudo, ao longo do tempo ela foi sendo diminuída e regulamentada por lei, a partir das reivindicações e conquistas dos próprios trabalhadores.

É interessante lembrar que a jornada de trabalho com mais de $16 \mathrm{~h}$ por dia era muito comum no período da servidão, até metade do século XIX. Apenas em 1889 o trabalhador conseguiu reduzi-la. No prefácio à edição alemã da obra Manifesto do Partido Comunista, Marx e Engels (1998, p. 95 - prefácio à edição alemã de 1890) comentam este fato: “[...] a jornada de oito horas de trabalho, a estabelecer por lei, que já o Congresso da Internacional, em 1866, e de novo o Congresso Operário de Paris, de 1889, haviam proclamado". No Brasil, essa conquista somente ocorreria com a Consolidação das Leis Trabalhistas, implantadas no governo de Getúlio Vargas. Nos últimos anos, muitas categorias profissionais reivindicam uma jornada de $6 \mathrm{~h}$ sem redução do salário; dentre elas, o Serviço Social, que a conquistou a partir de 2010. 
Essa luta pelo direito ao tempo reduzido e pela ampliação do tempo fora do trabalho (o chamado 'tempo livre') sem redução do salário o que, faça-se um parêntese, é muito diferente de flexibilizar a jornada, uma vez que esta se encontra em sintonia com a lógica do capital - deve estar intimamente articulada à luta contra o sistema de metabolismo social do capital que converte o 'tempo livre' em tempo de consumo para o capital, onde o indivíduo é impelido a 'capacitarse' para melhor 'competir' no mercado de trabalho, ou ainda a exaurirse num consumo coisificado e fetichizado, inteiramente desprovido de sentido. (LEFEBVRE, 203, p. 178).

O tempo também é utilizado para medir a produtividade do trabalhador. Um exemplo clássico do período fordista-taylorista é retratado no filme protagonizado por Charles Chaplin, Tempos modernos, mostrando que, após a crise de 1929, com desemprego em massa, a disputa por trabalho em fábricas era acirrada. A industrialização representava a modernidade, e o modo de produção capitalista era baseado na linha de montagem e na divisão alienada do trabalho. O tempo era medido através da lógica de maior produção no menor tempo possível, uma função repetitiva desempenhada pelo operário. Esta forma de medição e divisão do tempo era visível e concreta para o operário.

Com a ardilosa expansão do domínio capitalista de cunho neoliberal, a medida e a divisão do tempo passaram a ficar encobertas por um discurso que exalta a vantagem de o trabalhador escolher o horário e o local de sua produção. O trabalhador nem sempre se dá conta de que a flexibilização, enquanto uma das características da produção toyotista, é, na verdade, o controle do tempo de forma sutil, invisível à consciência na genericidade do indivíduo. O trabalhador serve ao tempo, sem perceber seu poder de determinação em todos os aspectos da vida cotidiana.

O rápido avanço da ciência e da tecnologia, atrelado ao modo de produção capitalista, tornam o tempo cada vez mais sutil no cotidiano se percebermos o quanto estamos sendo regidos pelo tempo e desenvolvendo uma verdadeira servidão em relação a ele, seja porque estamos sempre "correndo" atrás do tempo ou porque sempre falta tempo para realizarmos alguma atividade. Percebemos essa relação de servidão em relação ao mundo do trabalho alienado quando Marx (1993, p. 116) questiona: "[...] será a teoria do trabalho como mercadoria diferente de uma teoria disfarçada da servidão?"

O discurso sobre a importância do desenvolvimento tecnológico, da metade do século passado em diante, prometia mais tempo para o lazer, a família e o trabalho, enfim, mais tempo livre, tempo para o ócio criativo. Um dos tantos exemplos disso foi o marketing utilizado para a aceitação da comida congelada, que afirmava possibilitar mais tempo, praticidade e agilidade no preparo dos alimentos. Ou seja, era benefício garantido, já que a tecnologia iria presentear a vida cotidiana com uma significativa re- 


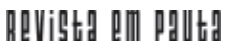

\} O TEMPO EM AGNES HELLER - GUIMARÃES, G. T. D. \}

DOI: $10.12957 /$ REP.2016.27855

dução do tempo necessário ao trabalho doméstico. Na verdade, esse foi um discurso falacioso do período desenvolvimentista ${ }^{22}$ brasileiro, quando se inicia a aliança com o capital financeiro, porta aberta para a posterior incorporação do neoliberalismo e, após isso, do neodesenvolvimentismo. O neoliberalismo, através do Consenso de Washington e $M$. Thatcher, a partir da década de 1970, promove uma série de ajustes econômicos que previam "medidas para acabar com a crise da dívida externa, a estagnação econômica e os altos índices inflacionários, [...] valorização dos capitais estrangeiros por meio de compras e expropriações maciças de bens públicos e da especulação financeira" (CASTELO, 2012, p. 623). No Brasil, esta política se instala a partir da década de 1980. Já o neodesenvolvimentismo

é um fenômeno recente e localizado, indissociável das particularidades da economia e da política brasileira na segunda metade dos anos 2000. A onda neodesenvolvimentista está diretamente relacionada às intrigas e conspirações palacianas entre as duas facções que disputam o controle da política econômica brasileira: a monetarista - braço direito do neoliberalismo e a autoproclamada 'desenvolvimentista' - braço esquerdo da ordem. (SAMPAIO JR., 2012, p. 678).

Atualmente, constatamos que, quanto maior o desenvolvimento tecnológico da sociedade, menor o tempo para outra atividade que não seja desenvolver um trabalho produtivo ao capital, ou o "lazer" sob a embalagem do consumo. A lógica mercantil é diminuir o tempo que o trabalhador dedica a si, possibilitando maior tempo para o trabalho excedente.

Para Heller (1991), o tempo é tão utilizado no cotidiano que também é empregado para substituir a distância em relação ao espaço. A autora exemplifica esta substituição da seguinte maneira: quando as pessoas precisam saber a distância que falta para alcançar determinado destino, não se referem à medida por quilômetros, mas empiricamente utilizam a medida do tempo: faltam $\mathrm{x}$ horas para chegar ao destino final, considerando o tempo característico de cada meio de transporte. Portanto, é muito corriqueiro utilizarmos o tempo de forma pragmática, como substituto na medida do espaço. Lefebvre (1991, p. 13) também compartilha da noção de que tempo e espaço estão entrelaçados e representam o cotidiano. Isto porque, "desvendando a cotidianidade, apresentar o tempo e o espaço ou o espaço no tempo" torna-se inerente à representação do vivido, embora seja uma dimensão pequena em relação ao todo que compõe a vida cotidiana do ser humano.

O tempo possui uma importância categórica, principalmente estando à sombra de todas as fases do capitalismo (comercial, industrial,

\footnotetext{
${ }^{22} \mathrm{O}$ desenvolvimentismo é considerado uma ideologia de apoio ao "nacionalismo, o protecionismo industrial e o positivismo. O auge do desenvolvimentismo ocorreu nos anos 1950-60. Nesse período o modelo desenvolvimentista aprofundou-se com a implementação do capital financeiro no Brasil". (CASTELO, 2012, p. 620).
} 
financeiro). Na atualidade, está relacionado com todos os aspectos da vida cotidiana em que se efetiva a objetivação genérica em-si. Destacando a relação com o trabalho, espinha dorsal do atual capitalismo financeiro, vê-se que a força de trabalho vendida, sob a forma de salário, tem estado sob a égide do trabalho precarizado, subordinado, penoso e explorador. O discurso que traduz estas condições é a falta de tempo: a falta de tempo para ficar com a família, falta de tempo para terminar uma atividade laboral, falta de tempo para o lazer.

Heller (1991, p. 389) destaca que, "junto à falta de tempo, retorna continuamente a experiência interior de excesso de tempo". Ela se refere ao excesso de tempo que não foi utilizado no trabalho abstrato e que envolve um aspecto subjetivo no âmbito da afetividade: o tédio. É aquele trabalho morto, enfadonho e rotineiro que não propicia o desenvolvimento de novas habilidades ou conhecimentos. O tratamento para romper com o tédio é a objetivação através de "atividades que tenham sentido, que permitam desenvolver as capacidades humanas" (HELLER, 1991, p. 389). Em outras palavras, o trabalho abstrato pode propiciar o tédio.

Podemos ser assaltados por esse sentimento no trabalho, em casa e em qualquer lugar, pois o tédio decorre de uma atividade rotineira, que não exige um desafio, não excita a curiosidade para executá-la ou oferece qualquer estímulo para o desenvolvimento das capacidades do ser humano. Desafiar a capacidade humana é desenvolver o trabalho na perspectiva humano-genérica, oportunizando crescimento, amadurecimento intelectual e afetivo, cujo resultado implique em satisfação, em prazer e dê significado para o processo de trabalho desenvolvido. Opõe-se a essa realidade o trabalho alienado, como geralmente ocorre nos modelos fordista, taylorista e toyotista. Esta perspectiva helleriana sobre o sentido do trabalho é compartilhada por Antunes (2003, p. 175):

[...] uma vida cheia de sentido fora do trabalho supõe uma vida dotada de sentido dentro do trabalho. Não é possível compatibilizar trabalho assalariado, fetichizado e estranhado com tempo (verdadeiramente) livre. Em alguma medida, a esfera fora do trabalho estará maculada pela desefetivação que se dá no interior da vida laborativa.

Segundo Heller (1991), a falta de tempo ou o excesso de tempo vivenciados pelo ser particular envolvem aspectos objetivos e subjetivos. Objetivos porque têm um significado social, externo, voltado para a sociedade. Subjetivos porque envolvem as sensações, emoções e sentimentos que somente podem ser vivenciados na particularidade de cada ser humano. O subjetivo não pode ser menosprezado em favor do objetivo, pois ambos são igualmente importantes para a realização da atividade proposta.

O aspecto objetivo é percebido também através da "falta de tempo" para a realização de tudo o que se deseja; já o aspecto subjetivo observase quando há envolvimento afetivo. Podemos dizer que a dimensão objetiva 


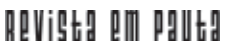

\} O TEMPO EM AGNES HELLER - GUIMARÃES, G. T. D. \}

DOI: $10.12957 /$ REP.2016.27855

acaba predominando, em detrimento do excesso de tempo que não foi utilizado envolvendo a subjetividade para a realização de tal atividade; ou seja, na execução da atividade houve um excesso de tempo disponível para a subjetividade que não foi utilizado, e há também uma falta de tempo em termos objetivos para realizar todas as atividades exigidas por uma sociedade capitalista exploradora. Para Heller (1991, p. 390), as atividades sensatas não são nem o discurso nem "as ações interpessoais intensas baseadas na igualdade", e sim as atividades realizadas com sentido.

\section{O ritmo do tempo}

Nos tempos atuais é muito comum ouvir a expressão "o tempo voa", deixando implícito que quanto maior o desenvolvimento da sociedade urbana, mais rapidamente passam as horas, os dias, os anos, como se o tempo pudesse ser mais rápido ou mais lento. Para Heller (1991, p. 390), o tempo é sempre o mesmo, ou seja, não passa rápida nem lentamente, pois "todo o fato é igualmente irreversível". Porém, o ritmo do tempo está relacionado ao período histórico e ao tipo de sociedade. Desse modo, não é o tempo que é mais rápido ou lento, e sim o ritmo do tempo que se torna mais rápido ou lento, dependendo dos fatores históricos, sociais e econômicos em que o indivíduo está inserido. "A aceleração do ritmo do tempo é (ao menos desde que surgiu o capitalismo) uma tendência geral da história" (HELLER, 1991, p. 390).

A autora ressalta que o ritmo do tempo acompanha o ritmo da história e, por isso, esse ritmo atinge todo ser humano, tanto no aspecto particular quanto no geral, influenciando mesmo as classes sociais que vivenciam os acontecimentos ou mudanças históricas ${ }^{23}$. É possível perceber que uma tribo indígena da Amazônia tem um ritmo diferente de outra "tribo" que vive numa grande metrópole. A questão não é o local, mas os fatos históricos que provocam uma mudança naquele povo ou sociedade.

Na concepção do materialismo histórico, o ser humano é criador de sua própria história, isto é, "o ser humano faz sua própria história; ele é o seu próprio criador" (FROMM, 1964, p. 25). O ser humano é produto do tempo passado na medida em que fez a história; é produto do tempo presente enquanto faz e é protagonista na história; e, como resultado do presente, "o ser humano modifica-se no curso da história. Ele é produto da história, transformando-se na evolução desta" (FROMM, 1969, p. 33). O protagonismo do indivíduo na história significa "sua libertação dos grilhões do determinismo econômico" (FROMM, 1964, p. 15).

\footnotetext{
${ }^{23}$ Em espanhol: "[...] afecta en primer lugar a las clases y estratos sociales que toman parte activa en los acontecimientos históricos o que son afectados por los cambios históricos".
} 
No transcurso histórico, o ritmo que afetou a sociedade foi acompanhado pelas fases do modo de produção: do comunal primitivo ao escravista, passando para o feudalismo e para o capitalismo. Houve uma notável aceleração no ritmo do tempo de acordo com cada fase, porém, o que realmente define o ritmo do tempo é a "diferença que existe entre quem participa ativamente e quem simplesmente sofre a influência da história" (HELLER, 1991, p. 390). Por exemplo, sofremos as influências das relações internacionais entre os países, das oscilações da bolsa de valores, das commodities, do preço do pãozinho de cada dia, mas não participamos ativamente destas negociações. São envolvimentos diferentes que irão refletir na sensação de aceleração ou lentidão no ritmo do tempo.

Heller (1991) comenta outra diferença no ritmo do tempo, pois o sujeito da história é protagonista nos acontecimentos, diferentemente de quem sofre apenas a influência dos eventos históricos. Lembramos que o ritmo de tempo a que ela se refere não é o da particularidade, mas um ritmo que é vivenciado historicamente por toda uma geração e, por isso, no âmbito da genericidade. Por exemplo, o ritmo de vida mercantil era diferente no taylorismo, que é diferente do ritmo de vida no toyotismo. A passagem de um modo de produção para outro vem acelerando o ritmo do tempo.

Hoje, sob a influência do toyotismo, o trabalhador assalariado deve ser polivalente, capaz de realizar várias funções, porque o trabalho excedente equivale ao excedente de três trabalhadores; isto é, polivalente porque corresponde a $3 \mathrm{em} 1$. Além disso, o trabalhador deve ser flexível no tempo, no turno, no local de trabalho, pois, independente do horário ou do local, ele ficará $24 \mathrm{~h}$ conectado à internet. Por isso, o ritmo do tempo é acelerado na mesma proporção do trabalho socialmente necessário que está subsumido ao capital. Sendo assim, o ritmo do tempo está diretamente vinculado ao "aumento da produtividade do trabalho social sob o capital se manifesta, portanto, como poder dominador das condições objetivas do trabalho sobre o trabalho vivo" (ESCURRA, 2016, p. 18).

Diante das transformações no mundo do trabalho e do modo como estas mudanças repercutem na sociedade, o trabalhador necessita estar constantemente se adequando ao ritmo do tempo ditado pelas forças produtivas do capital. "A vida, portanto, deve ser reordenada com frequência" (HELLER, 1991, p. 391), já que o ritmo de tempo do modo de produção imposto ao trabalhador provoca, na esfera da particularidade, um ritmo de tempo relativamente estável, sendo que "esta estabilidade é requerida, antes de tudo, pelo trabalho" 24 , não sob a forma de tempo livre, mas sob a égide do trabalho alienado.

O ritmo de vida regulado e o descanso não são sinônimos de tensão e relaxamento. Estas duas categorias se referem à obrigatoriedade do trabalho alienado e ao prazer de estar liberado dele. O descanso 
sob a forma de relaxamento é a contrapartida do trabalho alienado e constitui também um fenômeno de alienação ${ }^{25}$. (HELLER, 1991, p. 391).

\section{O momento}

Qual é o momento certo para se dizer ou realizar algo? Inúmeras vezes na vida cotidiana o indivíduo se depara com este dilema: em que momento se deve agir? Existe um momento certo e outro errado? Heller (1991) chama de "momento justo" o momento certo em que uma palavra ou ação é praticada e que gera um resultado positivo. O momento justo é o ponto de equilíbrio entre dois opostos, como é a representação da balança da justiça.

A autora destaca a importância da paciência para determinar o melhor momento de agir. A irreversibilidade se faz presente quando a escolha do momento for equivocada, de modo que seu resultado não poderá ser revertido, considerando que já faz parte do tempo passado.

Heller destaca que o momento justo se aplica principalmente à esfera da genericidade para-si, com ênfase na política, porque as consequências das decisões nesta área terão uma repercussão coletiva. "A eleição do momento justo pode ser decisiva para o destino de classes sociais ou povos inteiros. O talento político se revela, em grande medida, na capacidade de captar o momento justo" (HELLER, 1991, p. 392). Ela destaca que o momento justo também pode ser quando se cumpre o que foi contratado, chamado de "observância do término temporal prometido ou aceito" (HELLER, 1991, p. 392). Na sociedade atual, tudo é conduzido pelo tempo, tanto para iniciar uma atividade como para conclui-la. O término temporal vai estar de acordo com o momento social e histórico no qual está inserido, e cada sociedade utiliza uma maneira diferente para defini-lo.

$\mathrm{Na}$ perspectiva helleriana, o tempo não compreende apenas as objetivações genéricas em-si, mas também pode ocorrer na objetivação genérica para-si. A autora cita como exemplo a política, entendida como uma dimensão que vale para todos os indivíduos e não apenas para a particularidade. Quer dizer, a política é compreendida no sentido genuíno da pólis e, por isso, considerada uma objetivação no âmbito do ser genérico. Vale ressaltar que o ser genérico, na análise marxiana, decorre de uma consciência do ser humano enquanto existência coletiva, já que esta abrange uma consciência da constituição do Ser Social a partir das relações sociais e econômicas historicamente estabelecidas e que permitem a produção e

\footnotetext{
${ }^{24}$ Em espanhol: "[...] dentro de cada rasgo de la vida cotidiana el ritmo debe ser relativamente estable. Esta estabilidad es requerida ante todo por el trabajo".

${ }^{25}$ Em espanhol: "El ritmo de vida regulado y el descanso no son sinónimos de tensión y relajamiento. Estas dos categorías se refieren a la obligatoriedad del trabajo alienado y al placer de estar liberado de él. El descanso bajo la forma de relajamiento es la contrapartida del trabajo alienado y constituye también un fenómeno de alienación".
} 
reprodução da vida cotidiana. "O ser humano não é consciente de si mesmo só como indivíduo; é também consciente de si como membro da espécie humana, apreendendo assim uma 'essência humana' que é idêntica em si e nos outros homens" (MARX, 1993, p. 45).

A importância da dimensão da genericidade também é compartilhada por Antunes (2003, p. 177), que a compreende como uma dimensão em que é possível a transformação social, considerando que todos os aspectos da sociabilidade possibilitam engajamento e consciência para efetivar determinado propósito; "uma sociabilidade tecida por indivíduos (homens e mulheres) sociais e livremente associados".

\section{O tempo vivido}

O tempo vivido, além de ser antropomórfico como as características anteriores, diferencia-se dos demais porque é o único tipicamente subjetivo. Como não existe nenhum instrumento ou norma que possa quantificar o tempo interior vivenciado, ele é considerado como subjetivo na esfera da particularidade, o que Heller (1991, p. 392) chama de "experiência interior temporal". Ele é único e somente pode ser vivido enquanto experiência interior do próprio sujeito, ou seja, cada um o vivencia de forma diferente.

O tempo vivido não se refere ao tempo transcorrido, enquanto norma social e aplicação objetiva; refere-se, contudo, ao tempo vivido de forma subjetiva. Por exemplo, nos processos de trabalho, quando o envolvimento ocorre com prazer e satisfação, tem-se a sensação de que o processo foi breve, tal o envolvimento estabelecido e vivenciado com o mesmo. Isso geralmente ocorre quando a objetivação propicia o desenvolvimento da genericidade, geralmente através da arte, da ciência e do trabalho criativo. Se os processos de trabalho significam algo penoso, desgastante e alienado, sob os condicionantes da precarização das condições de trabalho os minutos se transformam em horas intermináveis. Neste sentido, o tempo vivido é dominado pela particularidade e por subjetivações presentes no trabalho vivo. Contudo, cabe ressaltar que o tempo vivido não é o tempo histórico, considerando que "a história de um dia engloba a do mundo e da sociedade" (LEFEBVRE, 1991, p. 8). É o tempo vivido na e pela história.

Os momentos carregados de emoções e sentimentos possuem um significado diferente para cada indivíduo e, de acordo com o grau de subjetividade com o qual são vivenciados, o conteúdo do acontecimento será breve ou longo. A experiência subjetiva interior, que ocorre na esfera da particularidade, é determinada pelo "conteúdo do acontecimento" 26 .

\footnotetext{
${ }^{26}$ Nas palavras da autora: "Es sobre todo el contenido del acontecimiento el que establece si la experiencia interior será muy larga o muy breve".
} 


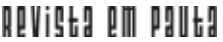

\} O TEMPO EM AGNES HELLER - GUIMARÃES, G. T. D. \}

DOI: $10.12957 /$ REP.2016.27855

Porém, é exatamente a condição de vivência temporal subjetiva que se torna o campo fértil da criatividade humana, evocando "fantasia, [...] memória e [...] imaginação"27. A memória chama o tempo passado para o presente, de acordo com o modo como a experiência foi vivenciada, ainda que seja irreversível; neste sentido, a filósofa húngara afirma: "[...] o tempo da memória é a mais subjetiva das experiências interiores temporais. O que eu revivo, com efeito é irreversível: a recordação é simplesmente um memorial desta irreversibilidade, e objetivamente não é nada mais (HELLER, 1991 , p. 393)"28.

O tempo passado nos remete à função da memória, no que diz respeito ao ser particular. Aquilo que foi gravado na memória é subjetivo, pois carrega uma série de fatores que determinam o significado daquela experiência. Assim, podemos ter memórias diferentes do mesmo fato. "Entre a particularidade do objeto-como-memória e a generalidade do objetocomo-mercadoria [...]" (STALLYBRASS, 1999, p. 93), existe uma representação social diferente para cada particularidade, embora esteja num contexto histórico aplicado genericamente e vivenciado coletivamente.

A fantasia e a imaginação direcionam para o tempo futuro, onde sonhos, projetos de vida e ideais são estabelecidos, e de onde abrolha a criatividade humana. Para o desenvolvimento das forças produtivas, o trabalho excedente é condição para a reprodução das condições objetivas do trabalho produtivo. Isso já é condição material para que a fantasia e a imaginação não tenham espaço na sociedade capitalista, com exceção dos processos de trabalho em que elas sejam instrumentos do trabalho produtivo, gerador de mais-valor.

[...] produtivo é aquele trabalho que se socializa graças a uma abstração, que tanto revela seu caráter natural de dispêndio de força humana quanto informa seu caráter social, conforme torna mensuráveis aquelas atividades necessárias para que uma sociedade se constitua em função da exploração do mais-valor. (GIANNOTTI, 2011, p. 91).

Na esfera da particularidade, quem se encontra diante do trabalho precarizado pode ter uma vivência oposta à fantasia e à imaginação. Segundo Lefebvre (1991, p. 7), "o inventário do cotidiano faz-se acompanhar de sua negação pelo sonho, pelo imaginário, pelo simbolismo, negação que supõe também a ironia dos símbolos e do imaginário". Portanto, a fantasia e a criatividade podem ser um epifenômeno do trabalho.

Além disso, o tempo livre pode ser perigoso, já que pode ser a oportunidade necessária para que, a partir da particularidade, o indivíduo

\footnotetext{
${ }^{27}$ No espanhol: "En la experiencia interior temporal tienen una particular función la fantasía, la memoria y la imaginación".

${ }^{28}$ Na versão em espanhol: "El tempo de la memoria es la más subjetiva de las experiencias interiores temporales. Lo que yo revivo, en efecto es irreversible: el recuerdo es simplemente un memento de esta irreversibilidad, y objetivamente no es nada más".
} 
atinja a esfera da genericidade, isto é, passe da objetivação em-si para a objetivação para-si. O tempo livre poderia ser o tempo necessário para refletir sobre e construir nova consciência; para o materialismo histórico, ele seria a possibilidade de alcançar a consciência de classe; para Heller (1991), a possibilidade de chegar à superação da cotidianidade através do não cotidiano.

De acordo com Mészáros (2011, p. 61), o tempo livre representaria o antídoto do trabalho produtivo alienante e explorado, "como antídoto ao excesso de tempo livre que envolve o perigo de um desenvolvimento da consciência social". Para Mandel (1982, p. 19), o tempo livre no socialismo representaria a liberdade "dum trabalho embrutecedor e que conceda suficiente tempo livre a toda a comunidade, para que esta possa desempenhar coletivamente as funções dirigentes na vida econômica e social". Portanto, para a sociedade capitalista, o tempo livre pode representar um grande perigo, colocando o sistema em risco.

Neste sentido, a engrenagem capitalista cria formas sutis, não percebidas ideologicamente, para que no tempo livre não seja desenvolvida a consciência política. Além disso, faz-se com que ele apenas exista enquanto sinônimo de consumo permanente das mercadorias que rapidamente se tornarão obsoletas, impulsionando o ciclo do consumo (dinheiro-mercadoria-dinheiro). A proposta do socialismo é a de que o ser humano se liberte dos tentáculos do capitalismo, para que seja possível conceder a emancipação humana enquanto protagonista de uma ação política e libertadora.

A emancipação humana só será plena quando o ser humano real e individual tiver em si o cidadão abstracto; quando como ser humano individual, na sua vida empírica, no trabalho e nas suas relações individuais, se tiver tornado um ser genérico; e quando tiver reconhecido e organizado as suas próprias forças (forces propres) como forças sociais, de maneira a nunca mais separar de si esta força social como força política. (MARX, 1993, p. 63).

\section{Considerações temporais}

É tempo de finalizar reflexões que são infinalizáveis, que estarão sempre em movimento e constante metamorfose histórica. Para tanto, cabe a pergunta: é possível pensar a sociedade ou a constituição ontológica do Ser Social sem considerar a relação entre tempo e trabalho? Certamente que não, pois trabalho é uma categoria fundante das relações sociais e econômicas, norteando o tipo de produção desenvolvido pela sociedade; já o tempo é indissociável de todo o processo que caracteriza atualmente o campo histórico e político vivenciado pela classe trabalhadora.

Na perspectiva helleriana, o tempo não é unicamente constitutivo do trabalho socialmente necessário; ele se caracteriza, contudo, pelo antro- 
pocentrismo que se configura na vida cotidiana, cujas peculiaridades são: a irreversibilidade, o limite, a medida e divisão, o ritmo, o momento justo e o tempo vivido. Estas características estão entrelaçadas, porém predominam de formas distintas entre as esferas da particularidade e da genericidade.

No que se refere à característica da irreversibilidade do tempo, o indivíduo na esfera da particularidade se conforma com o tempo pretérito e geralmente busca na religiosidade a justificação para a compreensão dos fenômenos social e economicamente produzidos. Esta perspectiva favorece o agrilhoamento do trabalhador de forma passiva, na medida em que este se conforma com as precárias condições de trabalho e com a expropriação da riqueza socialmente produzida. Para haver uma mudança de perspectiva no mundo do trabalho é necessária uma práxis social vinculada à esfera da genericidade; somente assim irá ocorrer a transformação das objetivações em-si para as objetivações para-si.

O limite do tempo, por sua vez, corresponde ao advento da morte humana, e a consequente aceitação como sendo natural ou ocasionada pode estar relacionada com a particularidade ou genericidade. A medida e divisão do tempo estão relacionadas com as formas de medida e divisão culturalmente praticadas, geralmente associadas à falta de tempo, ao trabalho alienado, à precarização nas condições de trabalho e à condição de servidão, que é típica no atual estágio do capitalismo financeiro. Em relação ao ritmo do tempo, ele é vivenciado no ritmo do trabalho que o modo de produção exige; assim, o ritmo do tempo na produção e gestão do padrão toyotista é invisibilizado pelas formas de flexibilização na gestão dos processos de trabalho, dando a falsa sensação de que o trabalhador é dono do próprio tempo. A mudança ocorre quando este ritmo é vivenciado intensamente através das objetivações para-si, isto é, quando o indivíduo se torna protagonista e consciente da luta coletiva da classe trabalhadora, da interferência (e não contemplação) no processo histórico. Este ritmo somente ocorre quando atrelado à esfera da genericidade.

O momento justo está fortemente ligado às escolhas e decisões conscientes dentro da questão da genericidade. O tempo vivido, numa dimensão subjetiva, pode estar associado ao verdadeiro tempo livre do indivíduo, uma condição sine qua non para que os trabalhadores desenvolvam uma consciência das potencialidades de transformação que a práxis social poderá realizar na esfera da genericidade. Numa perspectiva marxista, é condição para o desenvolvimento da consciência de classe.

Neste artigo, concluímos que os elementos que caracterizam o tempo devem ser levados em consideração para que se possam elaborar políticas públicas de defesa dos direitos sociais e que incidam sobre a proteção do trabalhador. É necessário que, ao elaborar estas políticas, considerese a inevitável ação na esfera da particularidade, na qual as objetivações em-si se materializam, para que, a partir dessa compreensão, se possa pla- 


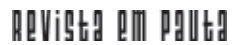

\} O TEMPO EM AGNES HELLER - GUIMARÃES, G. T. D. \}

DOI: $10.12957 /$ REP.2016.27855

nejar conscientemente uma política pública mediada teórica e ontologicamente na esfera da genericidade.

Por fim, neste artigo procuramos refletir sobre as características do tempo a partir da perspectiva helleriana, um tema que não é óbvio como parece ser. Com certeza ele faz parte da vida cotidiana e o indivíduo o vivencia, oscilando constantemente entre a particularidade e a genericidade. Na esfera da particularidade, a sociedade se reproduz na dinâmica do capitalismo; na esfera da genericidade, ela se transforma. Resta saber qual a esfera do tempo que o leitor irá escolher para vivenciar. 


\section{Referências}

ANTUNES, R. Os sentidos do trabalho: ensaio sobre a afirmação e negação do trabalho. São Paulo: Boitempo, 2003.

CASTELO, R. O novo desenvolvimentismo e a decadência ideológica do pensamento econômico brasileiro. Serviço Social e Sociedade, São Paulo: Cortez, n. 112, out./nov. 2012.

ESCURRA, M. F. O trabalho como categoria fundante do ser social e a crítica à sua centralidade sob o capital. Verinotio: dossiê (des)centralidade do trabalho, Rio de Janeiro: UFF, ano XI, n. 22, out. 2016.

SIGNIFICADOS. Estoicismo, Epicuricismo. Disponível em: $<w w w . s i g n i f i c a d o s . c o m . b r>$. Acesso em: 5 de jul. 2015.

FROMM, E. Conceito marxista do ser humano. Rio de Janeiro: Zahar, 1964. Meu encontro com Marx e Freud. Rio de Janeiro: Zahar, 1969.

GIANNOTTI, J. A. Marx, além do marxismo. Porto Alegre: L\&PM, 2011.

GUIMARÃES, G. T. D. Historiografia da cotidianidade: nos labirintos do discurso. Porto Alegre: EDIPUCRS, 2000.

. O não-cotidiano do cotidiano. In: GUIMARÃES, G. T. D. (Org.). Aspectos da teoria do cotidiano: Agnes Heller em perspectiva. Porto Alegre: EDIPUCRS, 2002a.

. Cotidiano e cotidianidade: limite tênue entre os reflexos da teoria e do senso comum. In: GUIMARÃES, G. T. D. (Org.). Aspectos da teoria do cotidiano: Agnes Heller em perspectiva. Porto Alegre: EDIPUCRS, 2002b. HELLER, A. O cotidiano e a história. Rio de Janeiro: Paz e Terra, 1989. 1991.

Sociología de la vida cotidiana. Barcelona: Ediciones Península,

- Uma crise global da civilização: os desafios futuros. In: A crise dos paradigmas em ciências sociais e os desafios para o século XXI. Rio de Janeiro: Contraponto, 1999.

IAMAMOTO, M. V. O Serviço Social na contemporaneidade: trabalho e formação profissional. São Paulo: Cortez, 2005.

LEFEBVRE, H. A vida cotidiana no mundo moderno. São Paulo: Ática, 1991. . Marxismo. Porto Alegre, RS: L\&PM Pocket, 2003.

MANDEL, E. Introdução ao marxismo. Porto Alegre: Movimento, 1982.

MARX, K. Manuscritos económico-filosóficos. Lisboa: Edições 70, 1993.

MARX, K.; ENGELS, F. Manifesto do Partido Comunista. São Paulo: Cortez, 1998. 


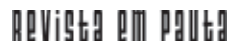

\} O TEMPO EM AGNES HELLER - GUIMARÃES, G. T. D. \}

DOI: $10.12957 /$ REP.2016.27855

MÉSZÁROS, I. A crise estrutural do capital. São Paulo: Boitempo, 2011.

REALE, G.; ANTISERI, D. História da filosofia. São Paulo: Paulus, 2003.

SAMPAIO JR., P. A. Desenvolvimentismo e neodesenvolvimentismo: tragédia e farsa. Serviço Social e Sociedade, São Paulo: Cortez, n. 112, out./nov. 2012.

STALLYBRASS, P. O casaco de Marx: roupas, memória, dor. Belo Horizonte: Autêntica, 1999.

WILDE, O. A alma do ser humano sob o socialismo. Porto Alegre: L\&PM Pocket, 2013.

Recebido em 18 de fevereiro de 2016.

Aprovado para publicação em 24 de novembro de 2016.

DOI: 10.12957/rep.2016.27855

\section{(c) (7)}

A Revista Em Pauta: Teoria Social e Realidade Contemporânea está licenciada com uma Licença Creative Commons Atribuição 4.0 Internacional. 